\title{
HOTSPOTS OF NARROW ENDEMISM: ADEQUATE FOCAL POINTS FOR CONSERVATION IN DENDROCHILUM (ORCHIDACEAE)
}

\author{
HENRIK Æ. PEDERSEN \\ Botanical Garden \& Museum, Natural History Museum of Denmark, University of Copenhagen, \\ Gothersgade 130, DK-1123 Copenhagen K, Denmark • henrikp@snm.ku.dk
}

KEY WORDS: area-selection, biodiversity, biogeography, complementarity, Malesia, orchids

The general aim of conservation is to ensure persistence of biodiversity value. Given certain measures (financial, logistic, etc.) the specific goal must be to maximize the amount of biodiversity value to be secured by these means. Several area selection methods are available for such purpose, and they represent very different conservation philosophies (Williams et al. 1996; Humphries 2006). Two fundamentally different approaches exist: (1) locating hotspots of species richness or narrow endemism, and (2) designating conservation areas according to complementarity methods.

Some authors define hotspots as areas with exceptional species richness or concentrations of endemic species and experiencing exceptional loss of habitat (e.g. Myers 1988; Myers et al. 2000). Frequently, however, the last criterion is disregarded (e.g. Prendergast et al. 1993; Williams et al. 1996) - a practice that I have chosen to adopt in the present study. Selecting hotspots of (species) richness has been a popular method, and with appropriate qualification hotspots can be used for high-scoring areas on any value scale and on any spatial scale (Humphries 2006). One advantage of the hotspot approach is that it deals with species occurrence data with apparent quantitative rigour. Hotspots of narrow endemism resemble hotspots of richness, but only endemic taxa are taken into account. As noted by Humphries (2006) this has the advantage of requiring data for only a subset of the species, and it is more likely to select for more highly complementary areas.

Complementarity methods are applied to designate the smallest selection of areas that in combination represent the maximum level of diversity (without necessarily including any hotspots). Complementary areas are generally more efficient than hotspots of either richness or rarity (Humphries 2006). The drawback of complementarity methods is that they either demand exhaustive searches using linear programming algorithms, or depend on heuristic algorithms that may not find optimal solutions (Csuti et al. 1997).

Taxonomic diversity (usually at species level) is by far the most commonly used measure of biodiversity. However, taxic diversity (Vane-Wright et al. 1991) and phylogentic diversity (Faith 1992; Mace et al. 2003; Pillon et al. 2006) are interesting alternatives. These measures are hardly sensitive to taxonomic inflation, and they add another dimension to the evaluation of conservation priorities.

The orchid genus Dendrochilum Blume has an Indo-Malesian distribution, ranging from Myanmar in the northwest across peninsular Thailand, Malaysia, Indonesia and the Philippines to southernmost Taiwan in the north and to Papua New Guinea in the southeast. The far majority of species are restricted to cool, humid, and often exposed conditions of montane forests. The genus contains an unusually high share of narrow endemics, and pronounced centres of species diversity are found in the high mountains of the Philippines (Pedersen 1997a), Borneo (Wood 2001), and Sumatra (Comber 2001). Surprisingly, only one Dendrochilum species is known from the mountain-rich island of New Guinea. The latest global taxonomic survey of Dendrochilum was that of Pedersen et al. (1997). Based on this checklist and subsequent changes, 268 species are currently accepted (Pedersen, unpubl. data).

No species of Dendrochilum are included in IUCN's latest red data list based on the global conservation status of individual species (http://www.redlist.org). However, among the 18 Dendrochilum taxa considered endemic to Sarawak in Borneo, Beaman et 
al. (2001) classified four species as vulnerable (VU), seven species and one variety as endangered (EN), and four species and one variety as critically endangered (CR). Only D. globigerum (Ridl.) J.J.Sm. was not regarded as threatened with extinction in the wild! Taking into account historical and current deforestation rates throughout most of Malesia and their estimated impact on orchid populations (Koopowitz 2001; Koopowitz et al. 2003) there is every reason to believe that corresponding analyses elsewhere would give a similarly gloomy result.

Evidently, active measures are urgently needed to protect representative taxonomic and phylogenetic diversity in Dendrochilum. Due to the unusually high share of narrow endemics in the genus, it is tempting to focus on hotspots of narrow endemism when setting the geographic conservation priorities. In the present study the conservational adequacy of focal points selected as hotspots of narrow endemism will be assessed by parallel evaluation of complementarity and of the overall level of diversity covered by this method.

\section{Methods}

The study was based on 22 semi-natural range units (Table 1). Among the 268 accepted species of Dendrochilum, the following had to be excluded from the analysis due to insufficient, unconfirmed, or entirely lacking distribution data: D. barbifrons (Kraenzl.) Pfitzer, D. coccineum H.A. Pedersen \& Gravend., D. croceum H.A. Pedersen, D. exalatum J.J.Sm., D. panduratum Schltr., D. warrenii H.A. Pedersen \& Gravend. For all species included, distribution data were extracted from the following sources: Smith (1933), Pedersen (1997a, 1997b, 2001), Pedersen et al. (1997, 2004), Beaman et al. (2001), Comber (2001), Wood (2001). Records explicitly based on uncertain identifications were disregarded. Infrageneric taxa above species level were designated according to Pedersen et al. (1997).

All range units were sorted in ascending order by their individual numbers of endemics, and the cumulative percent of endemics was plotted against that of the range units to form a Lorenz curve (Weiner \& Solbrig 1984; Calvo 1990). Hotspots of narrow endemism were then designated as the range units defining the steep part $(\mathrm{dy}>\mathrm{dx})$ of the curve.
TABLE 1. Survey and definitions of the 22 range units that were applied in the analyses of overall diversity patterns of Dendrochilum.

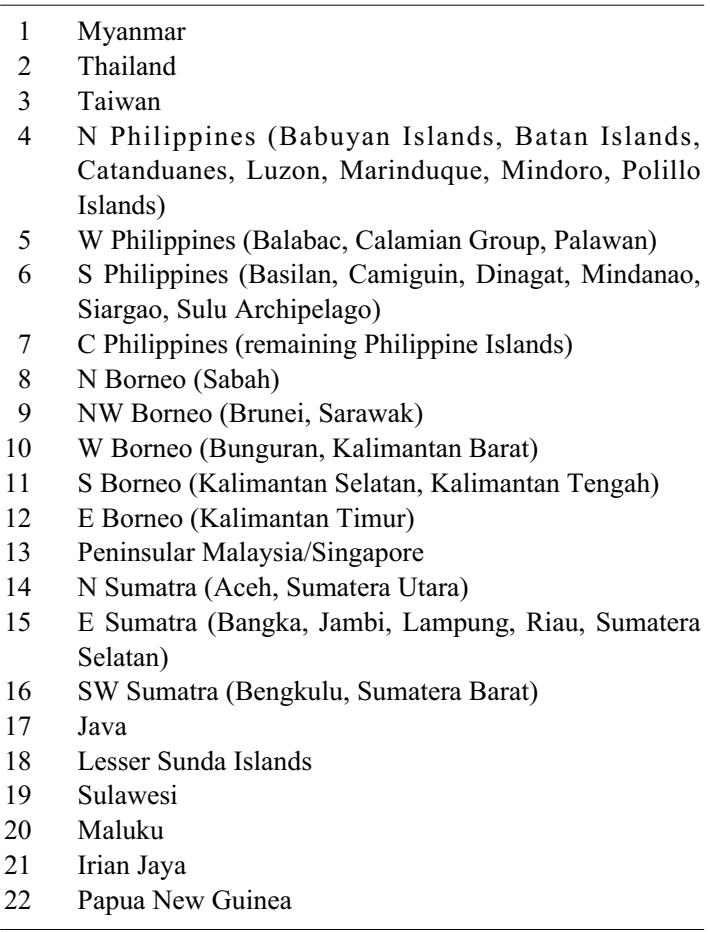

To compare regional exploration histories and evaluate the reliability of current interpretations of distribution patterns in Dendrochilum, a cumulative graph of narrow endemics as function of time was prepared for each hotspot. A cumulative graph of non-endemics in the entire geographic range was included for comparison.

Obviously, designation of hotspots of narrow endemism automatically secures a high degree of complementarity among the areas selected as focal points for conservation in a genus dominated by narrow endemics. However, this method does not necessarily ensure significant complementarity with regard to the representation of non-endemic species. To evaluate this problem, cluster analysis and ordination of all range units were performed on data for non-endemics only. Prior to the analyses, each non-endemic species was scored as present (1) or absent (0) in each range unit. All statistic operations were performed using the program NTSYSpc 2.0 (Rohlf 1998).

In the cluster analysis, floristic similarity was calculated for each pair of range units by the DICE algo- 
rithm (Dice 1945). The resulting distance matrix was used to construct a dendrogram describing the floristic similarity among all range units. The dendrogram was constructed by means of the UPGMA (unweighted pair-group method using arithmetic averages) algorithm (Legendre \& Legendre 1983). UPGMA is a polythetic agglomerative technique that appears to maximize the cophenetic correlation, and its use is recommended when there is no specific reason for choosing some other clustering technique (Sneath \& Sokal 1973).

Ordination was performed as principal components analysis (PCA; Sneath \& Sokal 1973). PCA is suited for the first iteration of analyses, because each character is given the same a priori weight, whereas intergroup distances are not taken into account. This method was originally developed for quantitative characters, but can also be used on binary characters (Gower 1966; Dunn \& Everitt 1982).

The extent to which hotspots of narrow endemism are identical with areas representing high levels of overall taxonomic diversity was assessed by direct comparison facilitated by parallel ranking of range units according to their relative individual richness at species, section, and subgenus level, respectively. For each taxonomic level the maximum taxon score was set at $100 \%$, and the lower scores were converted to percentages accordingly. In this way, relative taxonomic richness could be compared directly across taxonomic levels.

To obtain an estimate of the extent to which hotspots of narrow endemism ensure complementarity at higher taxonomic level, geographic affinities of regional Dendrochilum floras, characterized by diversity at section level, were summarized by ordination (PCA, see above). Two analyses were performed one in which each section (or subgenus, if not subdivided further) was scored as present (1) or absent (0) in each range unit; and one based on the number of species representing each section in each range unit. In the latter analysis, all characters (sections) were standardized prior to analysis (Gower 1971).

\section{Results}

The relative distribution of narrow endemics among range units can be seen from the Lorenz curve (Fig. 1). Seven range units define the steep part

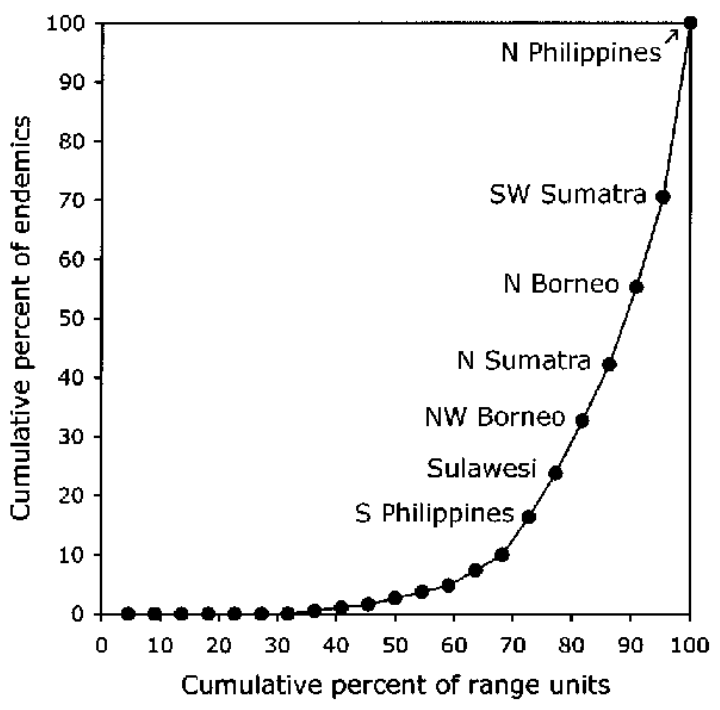

FIGURE 1. Lorenz curve demonstrating the markedly heterogenous distribution of narrowly endemic Dendrochilum species among the 22 range units. Seven range units make up the steep part of the curve $(d y>d x)$ and are designated as hotspots of narrow endemism.

(dy>dx) of the curve and can accordingly be designated as hotspots of narrow endemism: $N$ Philippines (56 endemics), SW Sumatra (29), N Borneo (25), N Sumatra (18), NW Borneo (17), Sulawesi (14), S Philippines (12).

The regional exploration histories of the seven hotspots of narrow endemism are illustrated in Fig. 2. Two distinct periods of exploration exist, that is approximately 1900-1940 and 1985-2000. This pattern is clearly reflected also by the general graph for non-endemic species, although a higher share of the non-endemics were described prior to 1900 .

According to both the cluster analysis (Fig. 3) and the PCA (Fig. 4), performed on data for non-endemic species only, four groups of hotspots of narrow endemism are highly complementary: N/SW Sumatra, Sulawesi, N/NW Borneo, N/S Philippines. In the PCA (Fig. 4), Sulawesi groups together with all remaining range units except $\mathrm{C}$ Philippines, but this is not obvious from the cluster analysis (Fig. 3). Indeed, the cluster analysis suggests higher complementarity and more pronounced geographic grouping among the non-hotspots than is evident from the PCA (Fig. 4).

In Table 2 all range units are ranked according to relative taxonomic richness at species, section and 


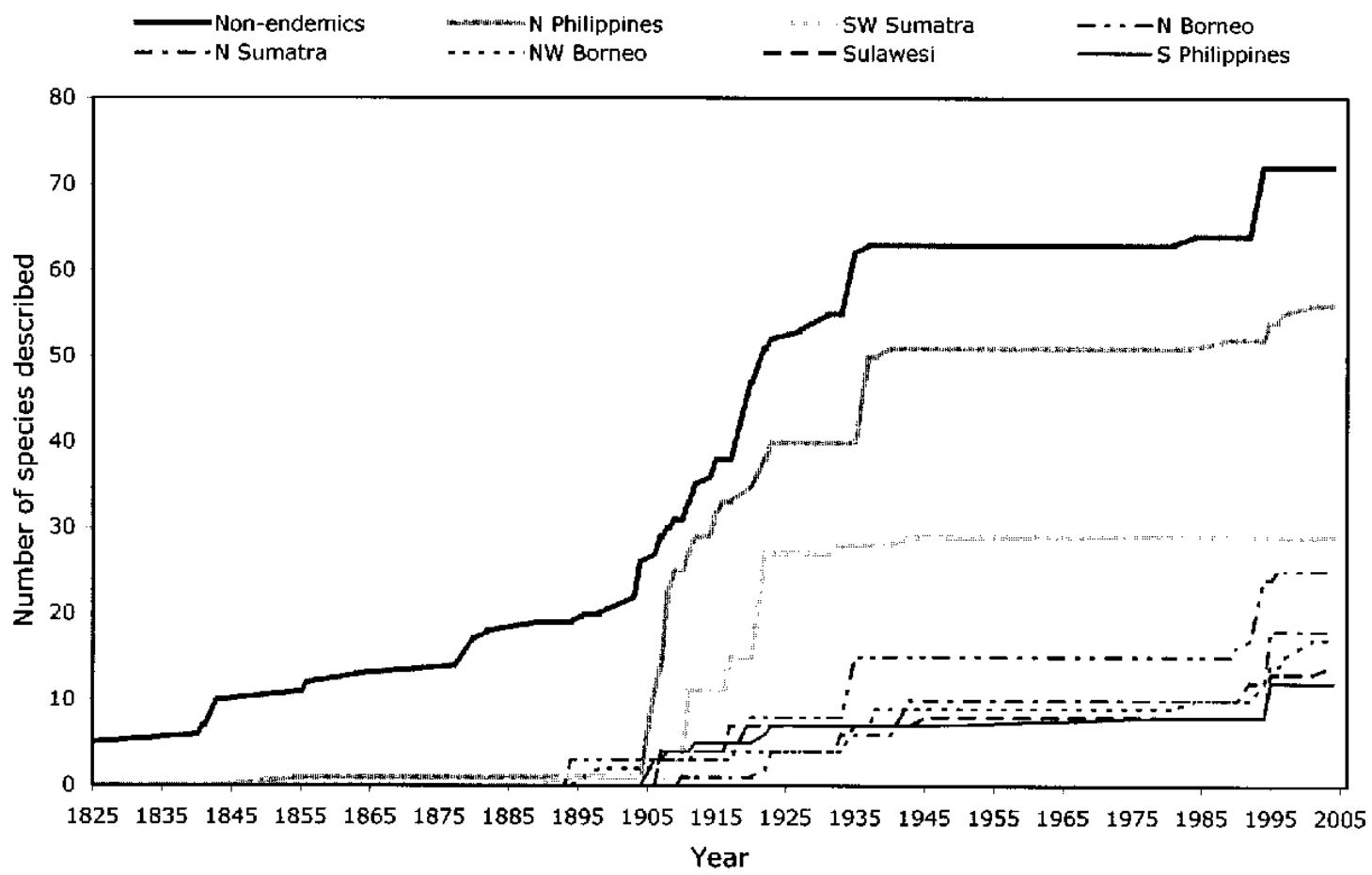

FIGURE 2. Cumulative graphs illustrating the exploration histories of regional endemic Dendrochilum floras. For all recognized hotspots of narrow endemism, a cumulative graph of endemics described from 1825 to 2005 is given. A cumulative graph based on all non-endemics is included for comparison.

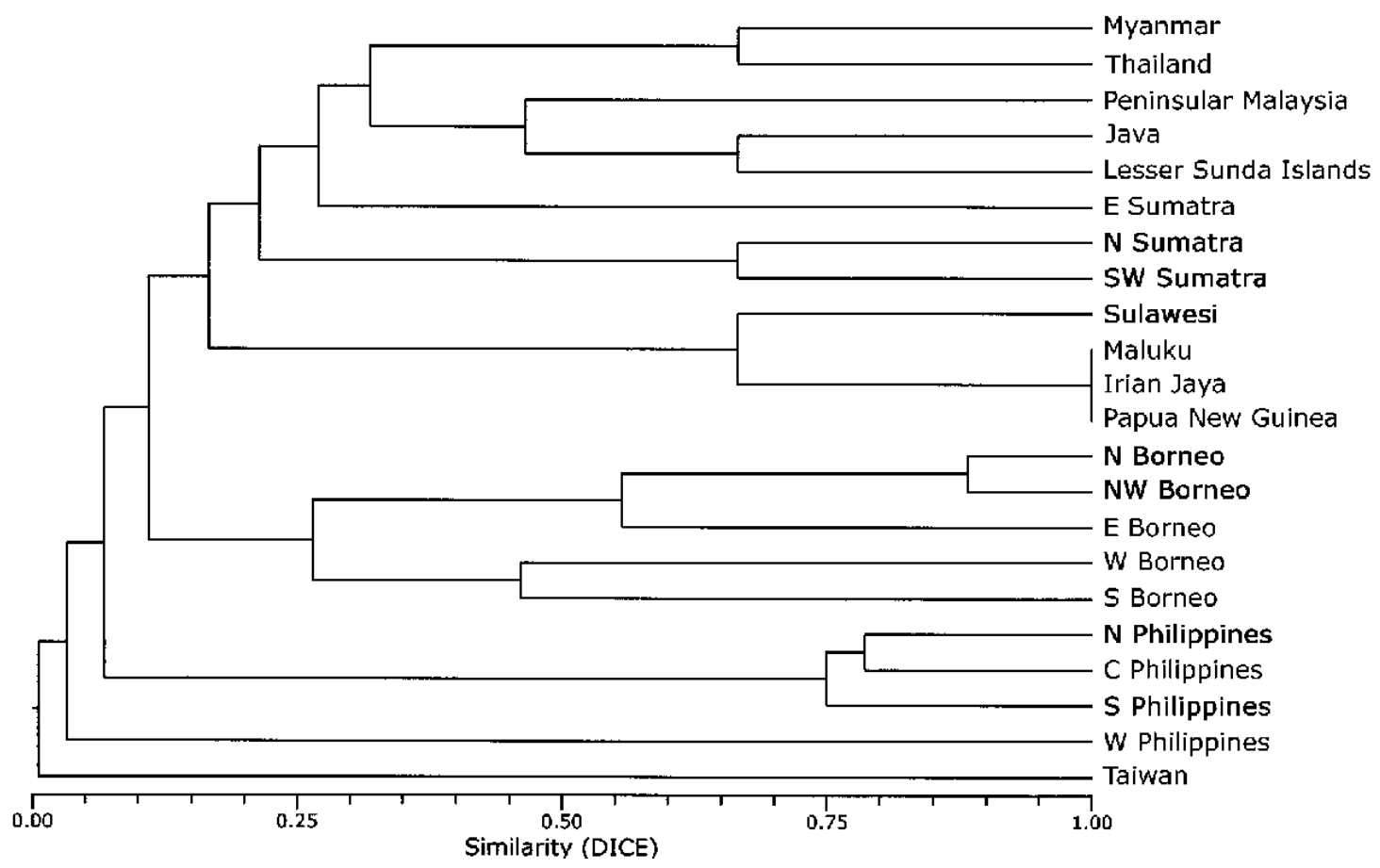

FigURE 3. Dendrogram showing the similarities of regional Dendrochilum floras (non-endemic species only). 


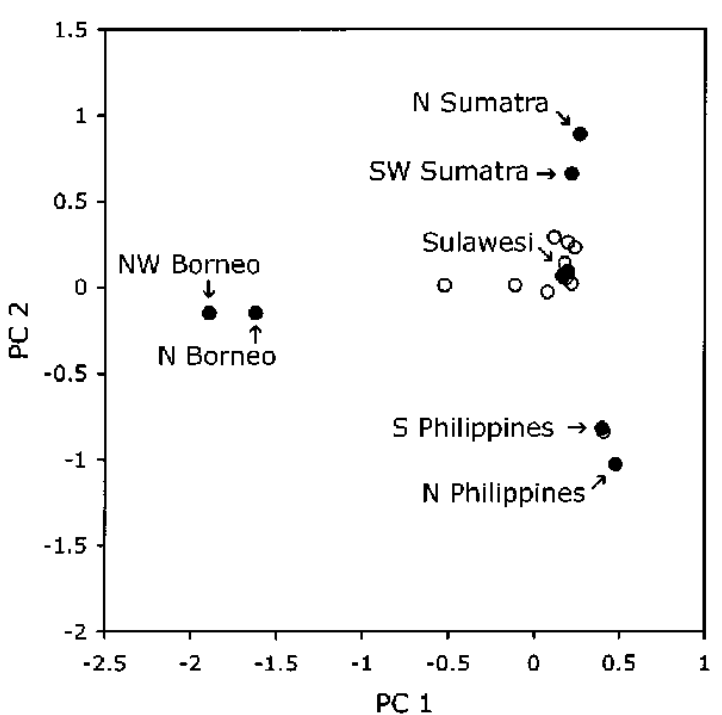

FIGURE 4. Mutual affinities of regional Dendrochilum floras. Plot from the first two principal components from the PCA performed on distribution data for non-endemic species only. Filled symbols represent hotspots of narrow endemism. The variation was $36.1 \%$ along PC axis 1 and $18.9 \%$ along $\mathrm{PC}$ axis 2 .

subgenus level, respectively, and in each column the hotspots of narrow endemism are highlighted to facilitate comparison.

According to both PCAs performed using sections as characters, N Philippines and N/NW Borneo appear highly complementary to each other and to all remaining range units (Figs 5-6). Within the latter group, the two analyses gave diverging results. Thus, according to the analysis based on presence/absence data (Fig. 5) Sulawesi groups together with $\mathrm{N}$ and SW Sumatra. In the plot from the analysis based on frequency data, on the other hand, Sulawesi is situated much closer to $\mathrm{S}$ Philippines (Fig. 6).

\section{Discussion}

NARROWLY ENDEMIC SPECIES. It appears directly from the Lorenz curve (Fig. 1) that the seven hotspots, though constituting less than $30 \%$ of the range units, hold nearly $90 \%$ of the narrow endemics. Consequently, using hotspots of narrow endemism as focal points for conservation is a very qualified method for securing a high share of this species group in Dendrochilum. Furthermore, it should be remembered that narrowly endemic species make up $71 \%$ of the genus.

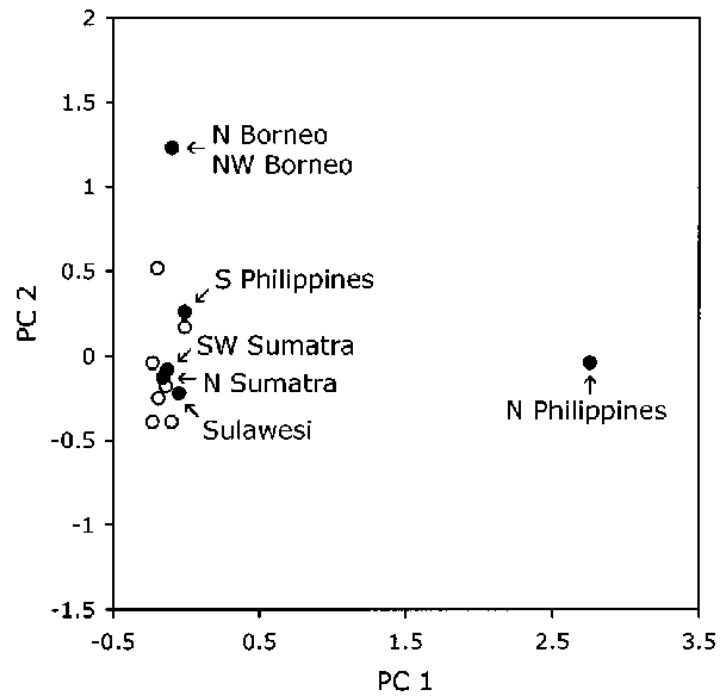

FiguRE 5. Mutual affinities of regional Dendrochilum floras. Plot from the first two principal components from the PCA performed on presence/absence data for sections. Filled symbols represent hotspots of narrow endemism. The variation was $38.5 \%$ along $\mathrm{PC}$ axis 1 and $21.1 \%$ along PC axis 2.

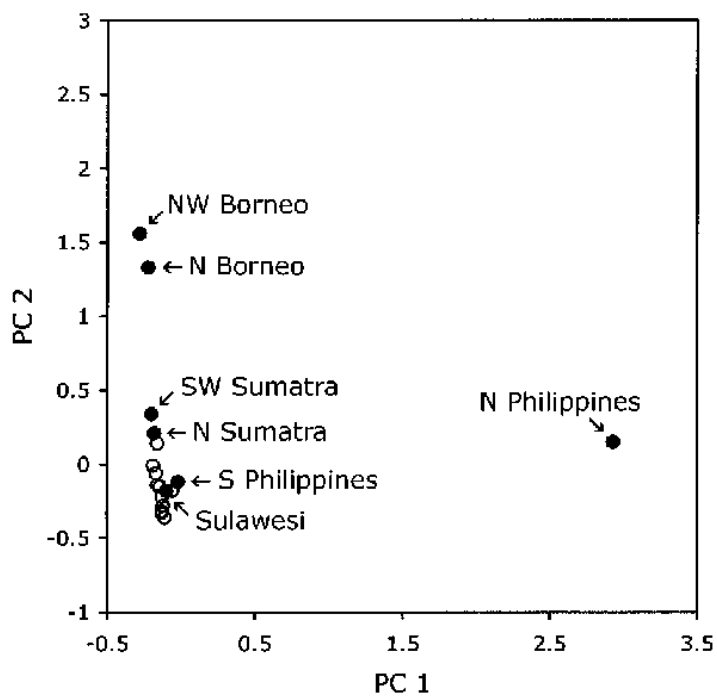

Figure 6. Mutual affinities of regional Dendrochilum floras. Plot from the first two principal components from the PCA performed on frequency data for sections. Filled symbols represent hotspots of narrow endemism. The variation was $43.2 \%$ along PC axis 1 and $26.1 \%$ along $\mathrm{PC}$ axis 2. 
Obviously, the credibility of the above finding depends on the reliability of current interpretation of geographic diversity patterns. After all, the steady rate at which new orchid species have been described over the past 25 years seems to continue (Cribb \& Govaerts 2005), and this might continuously change apparent geographic diversity patterns in several genera, including Dendrochilum. However, notwithstanding the heterogenous rate of exploration of each hotspot recognized in the present study, the hotspots constituting top-four (and their relative mutual importance) have remained unchanged for more than 60 years (Fig. 2). It should be noted that the graphs do not reflect historical perceptions of diversity patterns. They simply summarize the exploration histories of regional Dendrochilum floras according to current taxonomic and geographic interpretation. The observed constancy in diversity patterns over time indicates that current designation and ranking of most-important hotspots of narrow endemism can be considered sufficiently reliable.

Non-endemic species. - Three important observations can be made from Table 2: (1) the six range units with highest general species richness are identical with six hotspots of narrow endemism; (2) N Philippines, $\mathrm{N}$ and NW Borneo constitute top-three at both species and section level, and (3) the maximum subgenus score is shared among $\mathrm{N}$ and NW Borneo, $\mathrm{N}$ and $\mathrm{S}$ Philippines (and the non-hotspot C Philippines). Generally speaking, the most prominent hotspots of local endemism largely coincide with the range units showing the greatest taxonomic diversity in general and the greatest species richness in particular.

In order to maximize the level of complementarity (considering non-endemic species only), the areas of highest conservation priority should be selected among (rather than within) the four groups of hotspots that can be recognized in Figs 3-4 (viz. N/S Philippines, N/NW Borneo, N/SW Sumatra, and Sulawesi). With proper consideration, the use of hotspots of narrow endemism as focal points for conservation will also ensure a high level of complementarity with regard to non-endemic species.

Taxonomic versus phylogenetic diversity. - In the Philippine Dendrochilum flora, a clear correlation exists between the degrees of endemism and restrictedness to higher altitudes. If compared with distribution patterns expected for species having evolved before or after the Pleistocene, respectively, this correlation suggests that the majority of living (sub)montane species of Dendrochilum (including the far majority of narrow endemics in the Philippines) have evolved after the Pleistocene (Pedersen 1997a). Based on corresponding distribution data, Wood (2001) proposed a similar scenario for Borneo. The hypothesis that narrow endemics in Dendrochilum are largely (or universally) neoendemics resulting from local evolutionary radiation at high altitudes is consistent with preliminary molecular data (Barkman \& Simpson 2001).

The evolutionary hypothesis outlined above accentuates the importance of hotspots of narrow endemism in Dendrochilum, as conservation of "cradles of diversity" is now often considered a priority (Mace et al. 2003). At the same time, however, the hypothesis implies that using hotspots of narrow endemism as focal points for conservation in Dendrochilum, though ensuring a high species diversity, does not necessarily ensure a high phylogenetic diversity. In principle, the high species richness encountered in each hotspot of narrow endemism might represent recent prolific radiation at the end of just one major lineage - and not all such lineages might be secured if conservation efforts are directed to a few selected areas only. A marked discrepancy between geographic patterns of species diversity and estimated phylogenetic diversity, though on a different background, was recently demonstrated in the orchid genus Dactylorhiza (Pillon et al. 2006), and this potential complication for setting geographic conservation priorities should be considered for Dendrochilum as well.

No major cladistic analysis of Dendrochilum is yet available, so the geographic patterns of phylogenetic diversity cannot be estimated properly. However, the latest infrageneric classification of Dendrochilum (Pedersen et al. 1997), though not based on cladistic analysis, was hypothesized by the authors to reflect overall phylogenetic relationships in the genus. Tentatively accepting this hypothesis, geographic patterns of taxonomic diversity above species level can 
TABLE 2. Geographic diversity in Dendrochilum - parallel ranking of range units according to their relative individual richness at species, section, and subgenus level, respectively. For each taxonomic level the maximum score has been set at $100 \%$ and the lower scores converted accordingly. Hotspots of narrow endemism are given in bold. Range units with identical scores are listed alphabetically in each column. 100\% scores correspond to 71 species, 8 sections, and 3 subgenera, respectively.

SPECIES

SECTIONS

SUbGENERA

\begin{tabular}{|c|c|c|c|c|c|}
\hline N Philippines & 100 & N Philippines & 100 & C Philippines & 100 \\
\hline N Borneo & 79 & N Borneo & 86 & N Borneo & 100 \\
\hline NW Borneo & 76 & NW Borneo & 86 & N Philippines & 100 \\
\hline SW Sumatra & 59 & E Borneo & 57 & NW Borneo & 100 \\
\hline N Sumatra & 49 & S Philippines & 57 & S Philippines & 100 \\
\hline S Philippines & 36 & C Philippines & 43 & E Borneo & 50 \\
\hline E Borneo & 24 & N Sumatra & 43 & E Sumatra & 50 \\
\hline Sulawesi & 21 & E Sumatra & 29 & Java & 50 \\
\hline C Philippines & 20 & Java & 29 & Lesser Sunda Islands & 50 \\
\hline Java & 17 & Lesser Sunda Islands & 29 & Myanmar & 50 \\
\hline E Sumatra & 14 & Peninsular Malyasia & 29 & Peninsular Malaysia & 50 \\
\hline Peninsular Malaysia & 14 & SW Sumatra & 29 & N Sumatra & 50 \\
\hline W Borneo & 11 & W Borneo & 29 & S Borneo & 50 \\
\hline Lesser Sunda Islands & 6 & Myanmar & 14 & SW Sumatra & 50 \\
\hline S Borneo & 6 & S Borneo & 14 & W Borneo & 50 \\
\hline Myanmar & 1 & Sulawesi & 14 & Irian Jaya & 0 \\
\hline W Philippines & 1 & W Philippines & 14 & Maluku & 0 \\
\hline Irian Jaya & 0 & Irian Jaya & 0 & Papua New Guinea & 0 \\
\hline Maluku & 0 & Maluku & 0 & Sulawesi & 0 \\
\hline Papua New Guinea & 0 & Papua New Guinea & 0 & Taiwan & 0 \\
\hline Taiwan & 0 & Taiwan & 0 & Thailand & 0 \\
\hline Thailand & 0 & Thailand & 0 & W Philippines & 0 \\
\hline
\end{tabular}

be used as rough indirect indicators of phylogenetic diversity patterns in the genus.

It appears from Table 2 that $\mathrm{N}$ Philippines, $\mathrm{N}$ and NW Borneo constitute top-three at both species and section level, and that the maximum subgenus score is shared among $\mathrm{N}$ and $\mathrm{NW}$ Borneo, $\mathrm{N}$ and $\mathrm{S}$ Philippines (and the non-hotspot C Philippines). Consequently, the most prominent hotspots of narrow endemism at species level largely coincide with the range units showing the greatest relative taxonomic diversity at both species, section, and subgenus level. The immediate impression from Table 2 might be a marked negative correlation between this tendency and the taxonomic level, but it should be noticed that scores are less differentiated at section level, and even less so at subgenus level where only three different scores exist (Table 2).

In order to maximize the level of complementarity at sectional level, the areas of highest conservation priority should be selected among (rather than within) the three groups of hotspots that can be recognized in Figs 5-6 (viz. N Philippines, N/NW Borneo, and a group containing the remaining hotspots). With proper consideration, the use of hotspots of narrow endemism as focal points for conservation will also secure a high level of complementarity with regard to sections. The discrepancy between patterns obtained by analyses performed on presence/absence data (Fig. 5) and frequency data (Fig. 6), respectively, are small and should hardly affect selection of top-priority focal points when criteria concerning narrowly endemic species and non-endemic species are also taken into account (see above).

Does the hierarchical infrageneric classification of Pedersen et al. (1997) really reflect phylogenetic relationships in Dendrochilum? This question is obvi- 
ously of critical importance. Recent cladistic analyses based on ITS sequence data have questioned the phylogenetic consistency of our generic subdivision (Barkman 2001; Barkman \& Simpson 2001). However, the molecular phylogenetic analyses performed on Dendrochilum so far (Barkman 2001; Barkman \& Simpson 2001, 2002; Pedersen et al. 2004) cover only a minor part of the geographic range and proposed infrageneric taxa in the genus. At present, it is evident that our infrageneric classification (Pedersen et al. 1997) is not completely consistent with phylogentic relationships in Dendrochilum, but the magnitude of inconsistency remains to be settled.

CONClusions AND PERSPECTIVES. Current interpretation of diversity patterns in Dendrochilum appears reliable, and the most important aspects of diversity in this genus can be adequately preserved by conservation efforts focused on hotspots of narrow endemism. Indeed, the top-three hotspots of narrow endemism (N Philippines, SW Sumatra, N Borneo) also provide near-maximum levels of complementarity (assessed for sections and non-endemic species) as well as high taxonomic richness at both species, section, and subgenus level.

Based on world-wide distribution data for vascular plants, mammals, birds, reptiles, and amphibians, combined with regional degrees of threat through habitat loss, Myers et al. (2000) recognized 25 "biodiversity hotspots" - defined as areas where exceptional concentrations of endemic species are undergoing exceptional loss of habitat. The 25 biodiversity hotspots contain the remaining habitats of $44 \%$ of all vascular plant species, but their cover of primary vegetation has been reduced by $88 \%$ and now constitutes only $1.4 \%$ of the Earth's land surface. According to Myers et al. (2000) the 25 biodiversity hotspots exhibit a $68 \%$ overlap with Birdlife International's Endemic Bird Areas, $82 \%$ with IUCN/WWF International's Centres of Plant Diversity and Endemism, and 92\% with the most critical and endangered eco-regions of WWF/US's Global 200 List.

Among the biodiversity hotspots recognized by Myers et al. (2000), Sundaland, the Philippines, and Wallacea in combination accommodate all known species of Dendrochilum, and only D. longifolium
Rchb.f., D. pallidiflavens Blume, and D. uncatum Rchb.f. extend to neighbouring regions. Thus, all important diversity in Dendrochilum is confined to areas that are undergoing exceptional loss of natural habitats, but also to areas of the highest conservation priority in general. However, Dendrochilum is not equally represented throughout the above biodiversity hotspots. On the contrary, distinct hotspots of narrow endemism are found on a regional scale within both Wallacea (Sulawesi), the Philippines ( $\mathrm{N}$ and $\mathrm{S}$ Philippines), and Wallacea (N and NW Borneo, N and SW Sumatra).

The example of Dendrochilum highlights the need to assess biodiversity patterns on various geographic scales. Indeed, also assessments on a subregional scale would be needed to pinpoint exact conservation needs in Dendrochilum. Distinct local concentrations of species within the hotspots of narrow endemism recognized in the present study have been clearly demonstrated for $\mathrm{N}$ and S Philippines (Pedersen 1997a), as well as for N and NW Borneo (Wood 2001). Some of these small areas can even be characterized as centres of local endemism. Obviously, ample knowledge of such spatial substructures of diversity should be procured, preferably for a broad selection of organisms, and utilized in the process of area selection for conservation.

The analyses in the present study have not taken into account possible discrepancies between current and historical species occurrences, and they tell nothing about the present state of habitat fragmentation or other ecological conditions of potential conservation areas. Obviously, historical and ecological factors should be integrated in the area selection process in order to optimize the actual conservation effect (Tilman et al. 1994; Crisci et al. 2006).

ACKNOWLEDGMENTS. I am indebted to Ingeborg Nielsen for technical assistance with the illustrations.

\section{Literature Cited}

Barkman, T.J. 2001. Evolution of vegetative morphology in Mount Kinabalu high-elevation endemics: insights from the orchid genus Dendrochilum. Sabah Parks Nature J. 4: 9-24.

Barkman, T.J. \& B.B Simpson. 2001. Origin of highelevation Dendrochilum species (Orchidaceae) ende- 
mic to Mount Kinabalu, Sabah, Malaysia. Syst. Bot. 26: 658-659.

Barkman, T.J. \& B.B. Simpson. 2002. Hybrid origin and parentage of Dendrochilum acuiferum (Orchidaceae) inferred in a phylogenetic context using nuclear and plastid DNA sequence data. Syst. Bot. 27: 209-220.

Beaman, T.E., J.J. Wood, R.S. Beaman \& J.H. Beaman. 2001. Orchids of Sarawak. Natural History Publications (Borneo), Kota Kinabalu \& Royal Botanic Gardens, Kew.

Calvo, R.N. 1990. Inflorescence size and fruit distribution among individuals in three orchid species. Amer. J. Bot. 77: 1378-1381.

Comber, J.B. 2001. Orchids of Sumatra. Royal Botanic Gardens, Kew.

Cribb, P. \& R. Govaerts. 2005. Just how many orchids are there? In: A. Raynal-Roques \& A. Roguenant (eds), Actes du $18^{\mathrm{e}}$ congrès mondial et exposition d'orchidées, 11-20 Mars 2005, Dijon - France. Naturalia Publications, Turriers, pp. 161-172.

Crisci, J.V., O.E. Sala, L. Katinas \& P. Posadas. 2006. Bridging historical and ecological approaches in biogeography. - Aust. Syst. Bot. 19: 1-10.

Csuti, B., S. Polasky, P.H. Williams, R.L. Pressey, J.D. Camm, M. Kershaw, A.R. Kiester, B. Downs, R. Hamilton, M. Huso, M. \& K. Sahr. 1997. A comparison of reserve selection algorithms using data on terrestrial vertebrates in Oregon. Biol. Cons. 80: 83-97.

Dice, L.R. 1945. Measures of the amount of ecologic association between species. Ecology 26: 297-302.

Dunn, G. \& B.S. Everitt. 1982. An introduction to mathematical taxonomy. Cambridge University Press, Cambridge.

Faith, D.P. 1992. Conservation evaluation and phylogenetic diversity. Biol. Cons. 61: 1-10.

Gower, J.C. 1966. Some distance properties of latent root and vector methods used in multivariate analysis. Biometrika 53: 325-338.

Gower, J.C. 1971. A general coefficient of similarity and some of its properties. Biometrics 27: 857-871.

Humphries, C.J. 2006. Measuring diversity. In: E. Leadley \& S. Jury (eds), Taxonomy and plant conservation: the cornerstone of the conservation and the sustainable use of plants. Cambridge University Press, Cambridge, pp. 141-161.

Koopowitz, H. 2001. Orchids and their conservation. B.T. Batsford Ltd, London.

Koopowitz, H., P.S. Lavarack \& K.W. Dixon. 2003. The nature of threats to orchid conservation. In: K.W. Dixon, S.P. Kell, R.L. Barrett, \& P.J. Cribb (eds), Orchid conservation. Natural History Publications (Borneo), Kota Kinabalu, pp. 25-42.

Legendre, L. \& P. Legendre. 1983. Numerical ecology. Elsevier Scientific Publishing Company, Amsterdam.

Mace, G.M., J.L. Gittleman \& A. Purvis. 2003. Preserving the tree of life. Science 300: 1707-1709.

Myers, N. 1988. Threatened biotas: "hot spots" in tropical forests. Environmentalist 8: 187-208.

Myers, N., R.A. Mittermeier, C.G. Mittermeier, G.A.B. da Fonseca \& J. Kent. 2000. Biodiversity hotspots for conservation priorities. Nature 403: 853-858.

Pedersen, H.Æ. 1997a. The genus Dendrochilum (Orchidaceae) in the Philippines - a taxonomic revision. Opera Bot. 131: 1-205.

Pedersen, H.Æ. 1997b. Dendrochilum cootesii, a new protandrous species from the Philippines. Lindleyana 12: 205-207.

Pedersen, H.Æ. 2001. One new and one rediscovered species of Dendrochilum (Orchidaceae) from the Philippines. Lindleyana 16: 231-234.

Pedersen, H.Æ., B. Gravendeel \& D. Mudiana. 2004. Three new species of Dendrochilum (Orchidaceae) and their phylogenetic positions according to plastid and nuclear ribosomal ITS sequences. Blumea 49: 351-360.

Pedersen, H.Æ., J.J. Wood \& J.B. Comber. 1997. A revised subdivision and bibliographical survey of Dendrochilum (Orchidaceae). Opera Bot. 130: 1-85.

Pillon, Y., M.F. Fay, A.B. Shipunov \& M.W. Chase. 2006. Species diversity versus phylogenetic diversity: a practical study in the taxonomically difficult genus Dactylorhiza (Orchidaceae). Biol. Cons. 129: 4-13.

Prendergast, J.R., R.M. Quinn, J.H. Lawton, B.C. Eversham \& D.W. Gibbons. 1993. Rare species, the coincidence of diversity hotspots and conservation strategies. Nature 365: 335-337.

Rohlf, F.J. 1998. NTSYSpc. Numerical Taxonomy and Multivariate Analysis System. Version 2.0. User guide. Exeter Software, New York.

Smith, J.J. 1933. Enumeration of the Orchidaceae of Sumatra and neighbouring islands. Repert. Spec. Nov. Regni Veg. XXXII: 129-386.

Sneath, P.H.A. \& R.R. Sokal. 1973. Numerical taxonomy. The principles and practice of numerical classification. W.H. Freeman and Company, San Francisco.

Tilman, D., R.M. May, C.L. Lehman \& M.A. Nowak. 1994. Habitat destruction and the extinction debt. Nature 371: 65-66. 
Vane-Wright, R.I., C.J. Humphries \& P.H. Williams, P.H. 1991. What to protect? - Systematics and the agony of choice. Biol. Cons. 55: 235-254.

Weiner, J. \& O.T. Solbrig. 1984. The meaning and measurement of size hierarchies in plant populations. Oecologia 61: 334-336.

Williams, P., D. Gibbons, C. Margules, A. Rebelo, C.
Humphries \& R. Pressey. 1996. A comparison of richness hotspots, rarity hotspots and complementary areas for conserving diversity of British birds. Cons. Biol. 10: 155-174.

Wood, J.J. 2001. Dendrochilum of Borneo. Natural History Publications (Borneo), Kota Kinabalu \& Royal Botanic Gardens, Kew.

Henrik $\boldsymbol{E}$. Pedersen is an associate professor at the University of Copenhagen, where he acts as curator at the Botanical Garden \& Museum, Natural History Museum of Denmark. His research on the systematics, biogeography, ecology, and conservation biology of orchids is focused on Europe, the Mediterranean, and tropical Asia. He has a special interest in the orchid flora of Thailand and in the genera Dactylorhiza, Dendrochilum, Epipactis, and Ophrys. 